\title{
Clinical efficacy, safety, tolerability, and survival outcome of long-term inhaled iloprost treatment in the management of pulmonary arterial hypertension: Data from prospective multicenter observational OPTION study
}

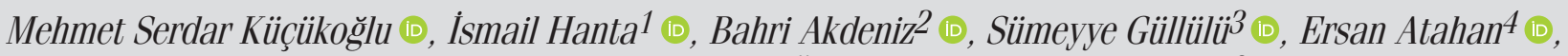

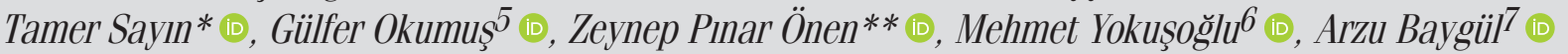 \\ Department of Cardiology, İstanbul University Cardiology Institute; İstanbul-Turkey \\ ${ }^{1}$ Department of Chest Diseases, Faculty of Medicine, Çukurova University; Adana-Turkey \\ ${ }^{2}$ Department of Cardiology, Faculty of Medicine, Dokuz Eylül University; İzmir-Turkey \\ ${ }^{3}$ Department of Cardiology, Faculty of Medicine, Uludağ University; Bursa-Turkey \\ ${ }^{4}$ Department of Chest Diseases, Cerrahpaşa Faculty of Medicine, İstanbul University; İstanbul-Turkey \\ ${ }^{5}$ Department of Chest Diseases, İstanbul Faculty of Medicine, İstanbul University; İstanbul-Turkey \\ ${ }^{6}$ Department of Cardiology, Gülhane Training and Research Hospital; Ankara-Turkey \\ ${ }^{7}$ Department of Biostatistics, Faculty of Medicine, Koç University; İstanbul-Turkey \\ Departments of *Cardiology, and **Chest Diseases, Faculty of Medicine, Ankara University; Ankara-Turkey
}

\section{ABSTRACT}

Objective: To evaluate clinical efficacy, safety and tolerability of long-term inhaled iloprost treatment in the daily practice for the management of pulmonary arterial hypertension (PAH).

Methods: A total of 115 patients with PAH on inhaled iloprost treatment were included. New York Heart Association (NYHA) functional class, brain natriuretic peptide (BNP) and N-terminal pro-B-type natriuretic peptide (NT-proBNP) levels, and 6-minute walk distance (6MWD) were recorded at baseline and at $3^{\text {rd }}$ to $24^{\text {th }}$ month visits. Safety and tolerability of iloprost treatment were also evaluated during follow-up, as were the survival, clinical worsening, and the related risk factors.

Results: The treatment was associated with an increase in the percentage NYHA functional class II (from $0.0 \%$ at enrolment to $36.2 \%$ at $24^{\text {th }}$ month visit) patients but no significant difference was noted in $6 \mathrm{MWD}$ values. Clinical worsening was observed in $63.5 \%$ patients, while survival rate was $69.6 \%$. NT-proBNP levels were significantly higher in non-survivors than in survivors $(\mathrm{p}=0.042)$. Cox regression analysis revealed the association of female sex [odds ratio (OR) $=0.318 ; 95 \%$ confidence interval ( $\mathrm{Cl}), 0.128-0.792 ; \mathrm{p}=0.014$ ] and scleroderma-related PAH (OR=0.347; $95 \% \mathrm{Cl}, 0.140-0.860 ; \mathrm{p}=0.022$ ) with significantly lower risk (3.14 fold and 2.88 fold, respectively) of mortality.

Conclusion: Our findings indicate favorable efficacy, safety, and tolerability of long-term iloprost treatment in the management of PAH, whereas improved NYHA functional class was not accompanied with a significant change in 6MWD values. Patient age was a risk factor for clinical worsening, while female sex, scleroderma subtype, and lower NT-proBNP levels were associated with significantly lower mortality risk.

Keywords: pulmonary arterial hypertension, iloprost, treatment outcome, safety, survival

Cite this article as: Küçükoğlu MS, Hanta I, Akdeniz B, Güllülü S, Atahan E, Sayın T, et al. Clinical efficacy, safety, tolerability, and survival outcome of long-term inhaled iloprost treatment in the management of pulmonary arterial hypertension: Data from prospective multicenter observational OPTION study. Anatol J Cardiol 2021; 25: 721-32.

\section{Introduction}

Pulmonary arterial hypertension (PAH) is a progressive and potentially fatal disease characterized by persistent vasoconstriction and remodeling of the resistance arterioles in pulmo- nary vasculature with increased pulmonary arterial pressure (PAP) and pulmonary vascular resistance (PVR) leading to progressive right ventricular failure (RVF) and death (1-4).

The development of pathway-specific targeted drugs has considerably improved the management of PAH by symptom

Address for Correspondence: Dr. Mehmet Serdar Küçükoğlu, İstanbul Üniversitesi Kardiyoloji Enstitüsü,

Kardiyoloji Anabilim Dalı, İstanbul-Türkiye

Phone: + 90212 459200/29513 E-mail: kucukoglu3@yahoo.com

Accepted Date: 26.04.2021 Available Online Date: 16.09.2021

(C) Copyright 2021 by Turkish Society of Cardiology - Available online at www.anatoljcardiol.com DOI:10.5152/AnatolJCardiol.2021.03009 


\section{HIGHLIGHTS}

- Efficacy, safety, and tolerability of inhaled iloprost therapy in pulmonary arterial hypertension (PAH) were evaluated.

- Long-term inhaled iloprost had favorable efficacy, safety, and tolerability profile.

- The New York Heart Association functional class was improved without a significant change in 6-minute walk distance values.

- Patient age was a risk factor for clinical worsening.

- Gender, PAH subtype, and N-terminal pro-B-type natriuretic peptide levels were associated with mortality risk.

reduction, deceleration of disease progression, and prolonged survival (5-7). Currently approved PAH-specific medicines address the three principal signaling pathways of pulmonary vasoregulation, including prostacyclin pathway (epoprostenol, iloprost, treprostinil, beraprost, and selexipag), nitric oxide pathway (sildenafil, tadalafil, vardenafil, and riociguat), and endothelin pathway (bosentan, ambrisentan, and macitentan) $(2,8)$.

lloprost is an inhaled prostacyclin-based therapy for PAH with vasodilatory and anti-proliferative effects (9-11), enabling significant improvements in exercise capacity, symptoms, and PVR and lesser incidence of clinical events in patients with PAH than with placebo $(2,9,12)$. Thus, inhaled iloprost is currently recommended as class I monotherapy for patients with PAH in New York Heart Association (NYHA) functional class III, as class Ilb monotherapy for patients in NYHA functional class IV, and as class IIb sequential combination therapy (add on to bosentan) for those in NYHA functional class II to IV $(2,13,14)$.

Inhaled iloprost has emerged as a major strategy in the treatment of PAH with certain advantages such as few systemic adverse effects, simple delivery, and vasodilation through different cellular mechanisms (15-17). However, its relatively short half-life necessitating frequent dosing (6-9 times per day) is considered likely to affect adherence (7), in addition to a paucity of clinical evidence regarding its therapeutic effectiveness in the long-term $(15,18)$.

This observational multicenter study was therefore designed to evaluate clinical efficacy, safety, and tolerability and survival outcome of long-term inhaled iloprost treatment in the management of PAH.

\section{Methods}

\section{Study population}

A total of 115 patients with PAH who were on inhaled iloprost treatment were included in this open-label, uncontrolled, multicenter, and non-interventional observational study with an enrolment period of February 2011 and February 2015 at 27 centers across Turkey. Adult ( $\geq 18$ years old) patients diagnosed with NYHA Class III-IV (requiring an improved exercise capacity and symptom control) PAH (idiopathic, familial, or secondary to scleroderma in the absence of interstitial lung disease) and initiated on iloprost treatment before enrolment owing to the insufficiency of standard therapies were included in the study. Presence of severe coronary heart disease or unstable angina, myocardial infarction within the last six months, decompensated cardiac failure if not under close medical supervision, severe arrhythmias, suspected pulmonary congestion, cerebrovascular events (e.g. transient ischemic attack, stroke) occurred within last three months, pulmonary hypertension because of venous occlusive disease, congenital or acquired valvular defects with clinically relevant myocardial function disorders not related to $\mathrm{PAH}$, and pregnancy or lactation were the exclusion criteria of the study.

Written informed consent was obtained from each patient following a detailed explanation of the objectives and protocol. The study was conducted in accordance with the ethical principles stated in the Declaration of Helsinki and approved by the Institutional Ethics Committee.

\section{Data collection}

Data on patient demographics (age, gender), PAH characteristics (clinical subgroup, duration, symptoms, Borg dyspnea score), NYHA functional class, iloprost treatment (monotherapy, combination therapy, inhalation dosage and frequency), co-morbid diseases, concomitant treatments, vasoreactivity test, hemodynamic parameters, biomarker levels [brain natriuretic peptide (BNP), N-terminal pro-B-type natriuretic peptide (NT-proBNP)], and 6-minute walk distance (6MWD) were obtained at the time of enrolment. Patients were followed up for 24 months after enrolment. Safety [adverse events (AEs), serious AEs (SAEs)] and tolerability of iloprost treatment were also evaluated during follow-up as were the survivorship status, clinical worsening, and the related risk factors.

Clinical worsening over the follow-up period was assessed on the basis of the presence of at least any one or more of the following markers; clinically significant deterioration of 6MWD compared with reference baseline values, worsening according to NYHA functional class, change or addition of drug treatment for PAH, PAH-related hospitalization, heart and/or lung transplantation, and survivorship status.

\section{Outcome measures}

The primary outcome measure was the efficacy of inhaled iloprost treatment on the basis of change from baseline reference 6MWD values during follow-up visits. Secondary outcome measures were the change in NYHA functional class and biomarker levels during follow-up, rates and risk factors for clinical worsening and survival outcome, as well as safety and tolerability of inhaled iloprost treatment.

Consistent with non-interventional design, duration of iloprost treatment, and timing of follow-up visits were at physicians' discretion according to the local prescribing information and routine medical practices. If the patients deteriorated on 
inhaled iloprost, the treating physician was free to initiate any alternative treatment, and the assessment of 6MWD was recommended before addition or change in therapy.

\section{Six-minute walk test}

The 6MWT was performed to determine 6MWD along with the degree of perceived exertion by means of Borg dyspnea scale $(6-20$ scale), both before and after the test $(2,19,20)$. 6MWT is used to determine functional exercise capacity, assess treatment efficacy, predict prognosis, and establish rehabilitation programs in patients with PAH, whereas 6MWD has been specified as the main clinical outcome in PAH and has been used as the primary end-point in multiple studies conducted for new PAH treatments $(2,19,21)$.

\section{Statistical analysis}

Although 160 patients were planned to be enrolled in the study according to the sample size calculation based on the standard deviation observed in the phase III study for patients with PAH NYHA functional class III (s observed, $67 \mathrm{~m}$; s expected, $<75 \mathrm{~m}$ ), only 115 patients who were eligible according to inclusion/exclusion criteria were included in the study.

Statistical analysis was done using IBM Statistical Product and Service Solutions for Windows, version 22.0 (IBM Corporation, Armonk, NY, USA). Fisher's exact test was used for comparison of categorical data and Mann-Whitney $U$ test for the comparison of non-normally distributed numerical variables. Change over time was analyzed via Wilcoxon signed rank test and repeated measures analysis of variance (ANOVA) with Bonferroni corrections. 6MWD analyses were based on constructing two one-sided hypotheses in the $95 \%$ confidence interval (CI). Survival analyses were analyzed using the Kaplan-Meier method. Cox regression analysis was used to identify the effect of risk factors on survival. For categorical variables, missing data of the patients were not included in calculations of percentages unless otherwise specified. Continuous data were expressed as mean \pm standard deviation and median (minimum-maximum), and categorical data were expressed percent. $P<0.05$ was considered statistically significant.

\section{Results}

Patient demographics and clinical characteristics at the enrolment ( $n=115)$

Mean age of patients was 50.7 (range, 19.2-84) years, and women comprised $79.1 \%$ of the study population. Duration of disease was median 1.9 years, whereas the clinical PAH subgroup was idiopathic PAH in $74.8 \%$ of patients (Table 1).

Dyspnea $(94.8 \%)$ was the most common symptom, followed by right heart failure symptoms (36.5\%). Median (minimum-maximum) Borg dyspnea score was 11.5 (6.0-20.0). Co-morbid diseases were evident in $35.6 \%$ of patients and abnormal chest X-ray and electrocardiogram findings in $93.7 \%$ and $88.7 \%$ of patients, respectively (Table 1).
Table 1. Patient demographics and baseline clinical characteristics (n=115)

Patient demographics

\begin{tabular}{llc}
\hline Age (year) & Mean \pm SD & $50.7 \pm 15.9$ \\
& Median (min-max) & $51.2(19.2-84.0)$ \\
Gender, $\mathbf{n}(\%)$ & Male & $24(20.9)$ \\
& Female & $91(79.1)$
\end{tabular}

PAH clinical subgroup, $\mathbf{n}(\%)$

Idiopathic PAH

PAH secondary to scleroderma

$26(22.6)$

Familial PAH

$3(2.6)$

PAH duration (year),

Mean \pm SD

$3.0 \pm 5.0$

Median (min-max)

$1.9(0.0-42.5)$

Hospitalization because of PAH within the last 20 (17.4) month, $\mathbf{n}(\%)$

PAH symptoms, $\mathbf{n}(\%)^{\mathrm{a}}$

$110(95.7)$

Dyspnea

$109(94.8)$

RHF symptoms (peripheral edema, jugular

congestion, change of weight, ascites, and/or hepatic pulse)

Cyanosis

Coughing

$21(18.3)$

Chest pain

$11(9.6)$

Syncope

Borg dyspnea score, median (min-max)

Co-morbid diseases, $\mathbf{n}(\%)$

$11.5(6.0-20.0)$

Hypertension

41 (35.6)

Type 2 diabetes

$15(13.0)$

$10(8.7)$

Abnormal chest $X$-ray findings

89 (93.7)

Pulmonary conus enlargement

79 (68.7)

Enlarged right heart silhouette

$76(66.1)$

Enlarged pulmonary segment and vessels

Globally enlarged heart

$63(54.8)$

Other

$15(13.0)$

Abnormal ECG findings ${ }^{b}, \mathrm{n}(\%)$

94 (88.7)

P pulmonale

50 (47.6)

ST depression

$52(49.0)$

Right bundle branch block

50 (47.2)

$\begin{array}{llc}\text { Arrhythmia } & \text { Sinus } & 89(84.7) \\ & \text { NA } & 16(15.3) \\ \text { Axis } & \text { Right } & 57(53.8) \\ & \text { Left } & 5(4.7) \\ \text { Vasoreactivity test, } \mathbf{n} & \text { Performed } & 95(88.0) \\ \text { (\%)c } & \text { Positive } & 6(6.4)\end{array}$

aNumber of patients with at least one PAH symptom. Missing data for bnine patients and, c20 patients (performed with iloprost in 38 patients)

ECG - electrocardiogram; max - maximum; min - minimum; PAH - pulmonary arterial hypertension; RHF - right heart failure; SD - standard deviation 


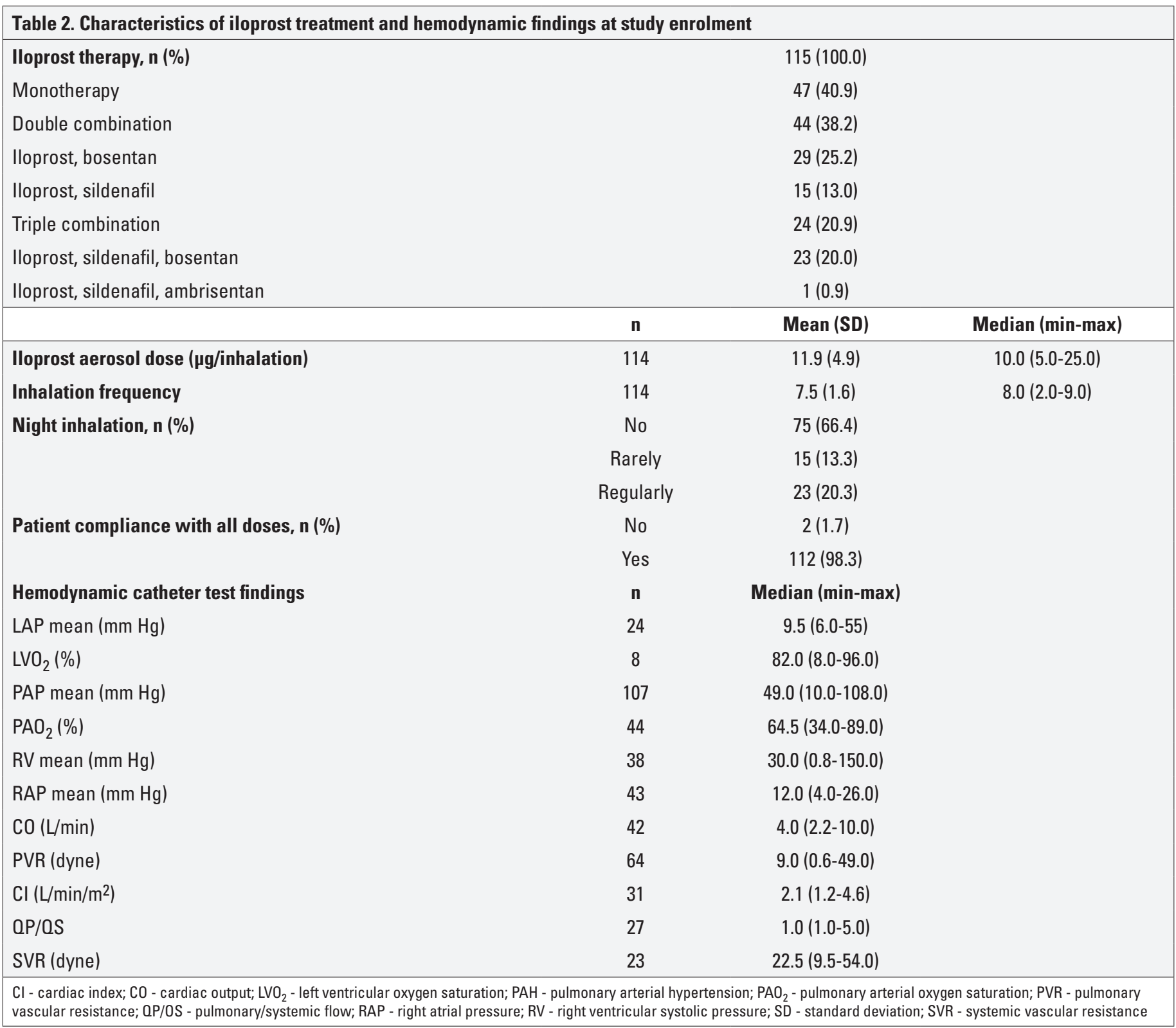

Characteristics of iloprost treatment and hemodynamic findings at study enrolment

At study enrolment, iloprost treatment involved monotherapy in $40.9 \%$ of patients, double combination in $38.2 \%$ (with bosentan in $25.2 \%$ and sildenafil in $13.0 \%$ ), and triple combination in $20.9 \%$ (with sildenafil and bosentan in $20.0 \%$ and with sildenafil and ambrisen$\tan$ in $0.9 \%$ ) of patients. Median aerosol dose was 10.0 (range, 5.025.0) $\mu \mathrm{g} /$ inhalation and median inhalation frequency was 8.0 (range, 2.0-9.0) times with no night inhalation in $66.4 \%$ of patients. Overall, $98.3 \%$ of patients were compliant with all doses (Table 2).

Hemodynamic catheter test findings at study enrolment are provided in Table 2.

Six-minute walk distance values at follow-up visits

Median 6MWD values measured at $3^{\text {rd }}$ month, $6^{\text {th }}$ month, $12^{\text {th }}$ month, $18^{\text {th }}$ month, and $24^{\text {th }}$ month follow-up visits were 351 (47-
$817), 360$ (26-780), 360 (26-780), 372 (140-760), and $358(60-750) \mathrm{m}$, respectively (Table 3 ).

No significant difference was noted between 6MWD values or change from baseline at follow-up visits (Table 3).

NYHA functional class and biomarkers at follow-up visits

During follow-up, an increase in the percentage of patients in NYHA functional class II (from $0.0 \%$ at enrolment to $36.2 \%$ at $24^{\text {th }}$ month visit) was noted along with a decrease in the percentage of patients in NYHA functional class III (from $87.8 \%$ at enrolment to $51.7 \%$ at $24^{\text {th }}$ month). Worsening in NYHA functional class was noted in $2.9 \%$ (3rd month) and $3.4 \%$ (24th month) of patients when compared with baseline status, and in $13.0 \%$ ( $24^{\text {th }}$ month) of patients when compared with previous visit status (Table 3).

Median (minimum-maximum) levels for BNP and NT-proBNP were $376.1(2.0-20016)$ and $875(24-7385) \mathrm{pg} / \mathrm{mL}$ at baseline, re- 


\begin{tabular}{|c|c|c|c|c|c|c|}
\hline 6MWD visit values (m) & $\mathbf{n}$ & Median (min-max) & & & & \\
\hline At enrolment (baseline) & 101 & $320(49-680)$ & & & & \\
\hline $3^{\text {rd }}$ month visit & 90 & $351(47-817)$ & & & & \\
\hline $6^{\text {th }}$ month visit & 89 & $360(26-780)$ & & & & \\
\hline $12^{\text {th }}$ month visit & 62 & $360(26-780)$ & & & & \\
\hline $18^{\text {th }}$ month visit & 50 & $372(140-760)$ & & & & \\
\hline $24^{\text {th }}$ month visit & 42 & $358(60-750)$ & & & & \\
\hline$P$-value ${ }^{1}$ & 0.058 & & & & & \\
\hline 6MWD-change from baseline $(\mathrm{m})$ & $\mathbf{n}$ & Median (min-max) & $P$-value ${ }^{2}$ & & & \\
\hline $3^{\text {rd }}$ month visit & 83 & $-14(-237-350)$ & 0.028 & & & \\
\hline $6^{\text {th }}$ month visit & 82 & $-10(-270-352)$ & 0.062 & & & \\
\hline $12^{\text {th }}$ month visit & 56 & $-35.5(-180-210)$ & 0.07 & & & \\
\hline $18^{\text {th }}$ month visit & 56 & $-15(-226-296)$ & 0.247 & & & \\
\hline $24^{\text {th }}$ month visit & 24 & $-20(-175-230)$ & 0.166 & & & \\
\hline$P$-value ${ }^{1}$ & 0.052 & & & & & \\
\hline NYHA functional class, $\mathbf{n}(\%)$ & $\begin{array}{c}\text { Baseline } \\
(n=115)\end{array}$ & $3^{\text {rd }}$ month (n=103) & $\begin{array}{l}24^{\text {th }} \text { month } \\
(n=58)\end{array}$ & & & \\
\hline Class I & 0 & 0 & 0 & & & \\
\hline Class II & 0 & $32(31.1)$ & $21(36.2)$ & & & \\
\hline Class III & $101(87.8)$ & $60(58.2)$ & $30(51.7)$ & & & \\
\hline Class IV & $14(12.2)$ & $11(10.7)$ & $7(12.1)$ & & & \\
\hline NYHA worsening, $\mathbf{n}(\%)$ & $\begin{array}{c}\text { Baseline } \\
(n=115)\end{array}$ & $3^{\text {rd }}$ month (n=103) & $\begin{array}{c}24^{\text {th }} \text { month } \\
(n=58)\end{array}$ & & & \\
\hline \multirow[t]{2}{*}{ From baseline } & Class II to III & - & - & & & \\
\hline & Class III to IV & $3(2.9)$ & $4(3.4)$ & & & \\
\hline \multirow[t]{2}{*}{ From the previous visit } & Class II to III & - & $6(11.1)$ & & & \\
\hline & Class III to IV & - & $1(1.9)$ & & & \\
\hline \multirow[t]{2}{*}{ Biomarker levels ${ }^{3}$} & \multicolumn{2}{|c|}{ Baseline (n=115) } & \multicolumn{2}{|c|}{$3^{\text {rd }}$ month (n=103) } & \multicolumn{2}{|c|}{$24^{\text {th }}$ month $(n=58)$} \\
\hline & $\mathbf{n}$ & median (min-max) & $\mathbf{n}$ & median (min-max) & $\mathbf{n}$ & median (min-max) \\
\hline BNP (pg/mL) & 27 & $376.1(29-20016)$ & 17 & 389 (54-15783) & 4 & $1044.1(78-1994)$ \\
\hline NT-proBNP (pg/mL) & 29 & $875(24-7385)$ & 23 & $866(21-8299)$ & 10 & $858.6(117-2614)$ \\
\hline
\end{tabular}

spectively, with no significant change from baseline levels at follow-up visits (Table 3).

\section{Treatment regimens during follow-up}

At $3^{\text {rd }}, 6^{\text {th }}, 12^{\text {th }}, 18^{\text {th }}$, and $24^{\text {th }}$ month visits, patients were treated with monotherapy in $35.0 \%, 31.0 \%, 29.1 \%, 28.6 \%$, and $24.6 \%$ of patients; as double combination in $41.7 \%, 45.0 \%, 48.1 \%$, $41.3 \%$, and $49.1 \%$ of patients; and as triple combination in $22.3 \%$, $24.0 \%, 22.8 \%, 30.2 \%$, and $26.3 \%$ of patients, respectively (Fig. 1).

\section{Risk factors for clinical worsening and mortality}

Overall, clinical worsening was observed in $73(63.5 \%)$ patients within median 12.0 months $(95 \% \mathrm{Cl}, 6.9-17.2)$, and the sur- vival time was 43 months and the survival rate was $69.6 \%$ with mortality in 35 (30.4\%) patients (Table 4, Fig. 2).

Patient age was significantly higher for those with than without clinical worsening (mean \pm SD, $53.4 \pm 14.2$ vs. $46.6 \pm 17.4$ years, $p=0.041$ ), and NT-proBNP levels were significantly higher in non-survivors than in survivors [median (minimum-maximum), 1291 (24-10848) vs. 622 (14-5778) pg/mL, $p=0.042]$, whereas other parameters had no significant impact on clinical worsening or mortality (Table 4).

\section{Cox regression analysis for risk factors of mortality}

Cox regression analysis revealed the association of female $\operatorname{sex}(0 \mathrm{R}=0.318 ; 95 \% \mathrm{Cl}, 0.128-0.792 ; \mathrm{p}=0.014)$ and sclerodermarelated $\mathrm{PAH}(\mathrm{OR}=0.347 ; 95 \% \mathrm{Cl}, 0.140-0.860 ; \mathrm{p}=0.022)$ with signifi- 


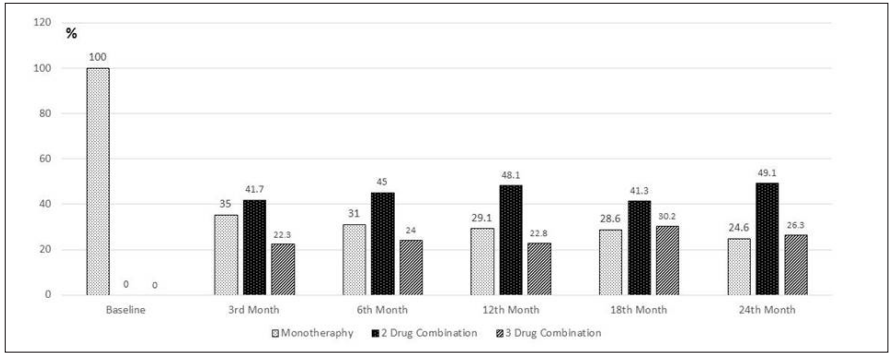

Figure 1. lloprost-based treatment regimens during follow-up
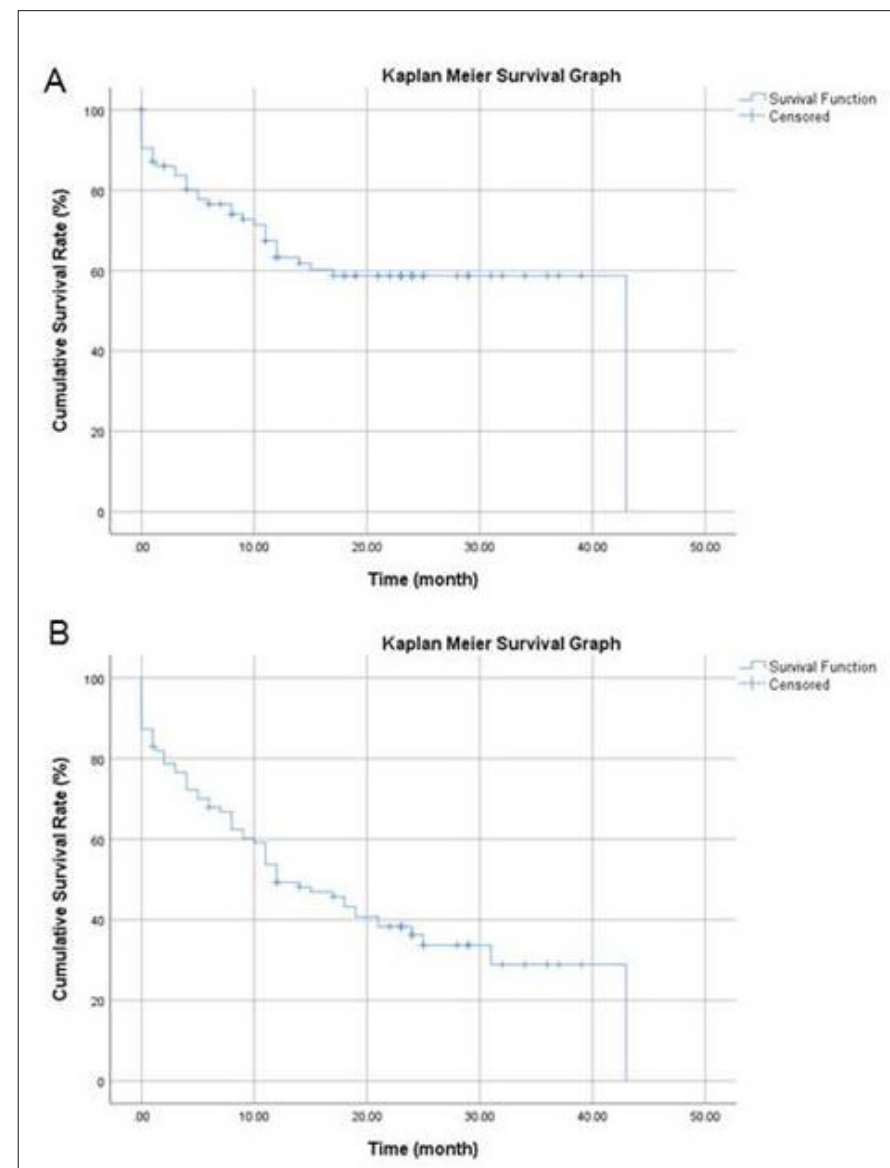

Figure 2. Kaplan-Meier analysis for, a) survival time (month) and, b) clinical worsening time (month) as calculated according to hospitalization, death, transplantation, and worsening in walking distance test

cantly lower risk ( 3.14 fold and 2.88 fold, respectively) of mortality. Age and NYHA functional class variables had no significant impact on risk of mortality (Table 5).

No significant difference was noted in mean (SE, 95\% CI) survival time with respect to age groups $[<30$ years: $33.8(2.9,28.2-$ $39.5)$ months, 30 to 49 years: $31.2(3.1,25.1-37.4)$ months, 49.1 to 64 years: 19.5 (2.0, 15.5-23.5) months, 64.1 to 74 years: 22.6 (2.3, 18.2-27.1) months, Log rank $p$ value 0.349$]$.

\section{Safety data}

Overall, a total of 29 AEs were reported and the most frequently observed AEs were dyspnea $(27.6 \%)$, cyanosis $(13.8 \%)$, and cough $(13.8 \%)$. There were 124 SAEs and the most frequent- ly reported SAEs were RVF $(13.7 \%)$, dyspnea $(9.7 \%)$, respiratory failure $(8.9 \%)$, and pneumonia (8.9\%) (Table 6$)$.

There were 35 deaths $(30.2 \%)$ reported in this study, none of which was considered related to the treatment (causality not reported in one patient). The most frequent reason for death was AEs $(62.1 \%)$, which was related to the primary diagnosis of the patients, resulting in cardiovascular deterioration and consequent mortality.

\section{Discussion}

Our findings revealed improved NYHA functional class status, which was not accompanied with significant improvement in 6MWD from enrolment to $24^{\text {th }}$ month visit in patients with PAH under iloprost treatment. Clinical worsening was noted in $63.5 \%$ of patients within a median 12-month of therapy, whereas survival rate was $69.6 \%$. Clinical worsening was more likely in older patients, and NT-proBNP levels were significantly higher in nonsurvivors than in survivors. Female gender and sclerodermarelated PAH were determined to be associated with significantly lower mortality risk; however, neither age nor NYHA functional class had a significant impact on mortality risk.

During the study period, the rate of iloprost monotherapy decreased (from $40.9 \%$ at enrolment to $24.6 \%$ at $24^{\text {th }}$ month visit) alongside an increase in the rate of double (from $38.2 \%$ to $49.1 \%$ ) and triple (from $20.9 \%$ to $26.3 \%$ ) combinations. This seems consistent with the widespread use of sequential combination therapy in current clinical practice worldwide as recommended by the international guidelines for PAH treatment $(2,15,22)$.

Accordingly, our findings support the data from previous clinical trials on safety and efficacy of iloprost aerosol therapy in NYHA functional class III or IV patients with PAH either in monotherapy or in combination with other specific drugs targeting endothelin and nitric oxide pathways $(9,10,15,23-26)$. Notably, data from a recent meta-analysis of 10 studies in a total of 370 patients treated with inhaled iloprost indicated that it is associated with a significant improvement in 6MWD in the short-medium and prolonged treatment groups, as well as with the improved functionality by at least one class in $48.7 \%$ of patients (23).

Albeit a tendency for a considerable increase was noted in 6MWD values from baseline within the first three months of therapy (from median $320 \mathrm{~m}$ to $350 \mathrm{~m}$ ), our findings revealed no significant difference between 6MWD values or change from baseline recorded at follow-up visits. In a meta-analysis included six datasets of PAH therapies with random controlled trials (RCT) and corresponding open-label extension studies, baseline 6MWDs were reported to range from a mean of 330 to $368 \mathrm{~m}$ and considered to be reflective of a patient population in predominantly WHO functional class III (27). Authors indicated the overall fixed-effects estimate of mean difference in change in 6MWD from pivotal RCT baseline and from baseline before first active dose to be $14.6 \mathrm{~m}(95 \% \mathrm{Cl}, 5.6-23.5)$ and $20.5 \mathrm{~m}(95 \% \mathrm{Cl}$, 10.430.7), respectively (27). However, in a meta-analysis of 22 RCTs assessing $6 \mathrm{MWD}$ in patients with PAH, changes in 6MWD were concluded not to reflect benefit in clinical outcomes related to 


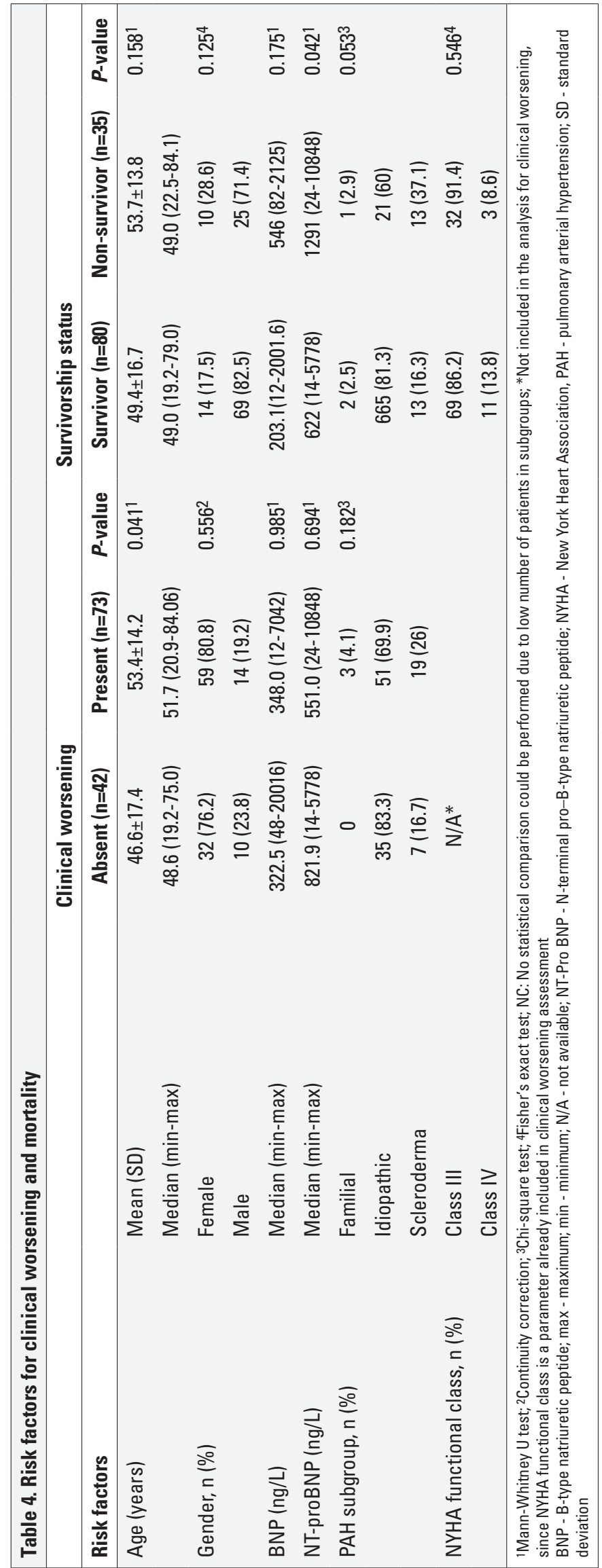

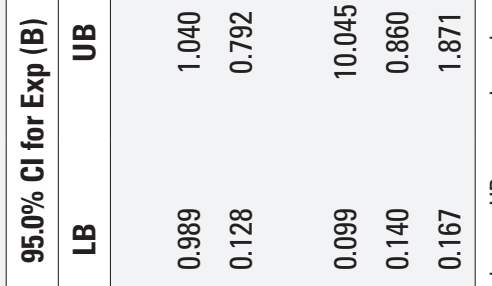

㠃齐

म่

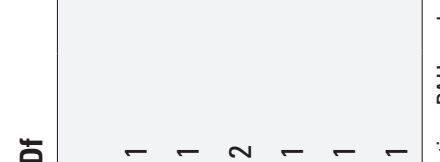

플

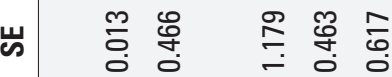

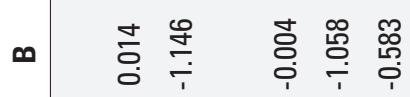

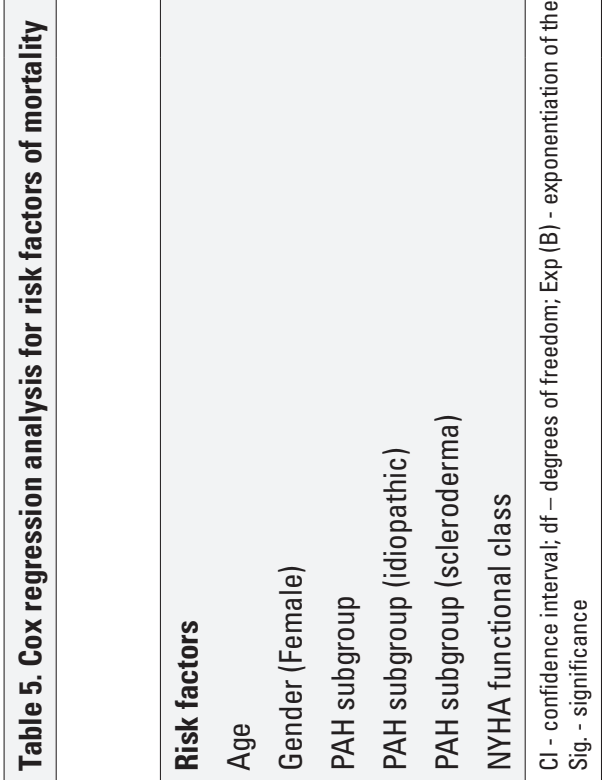




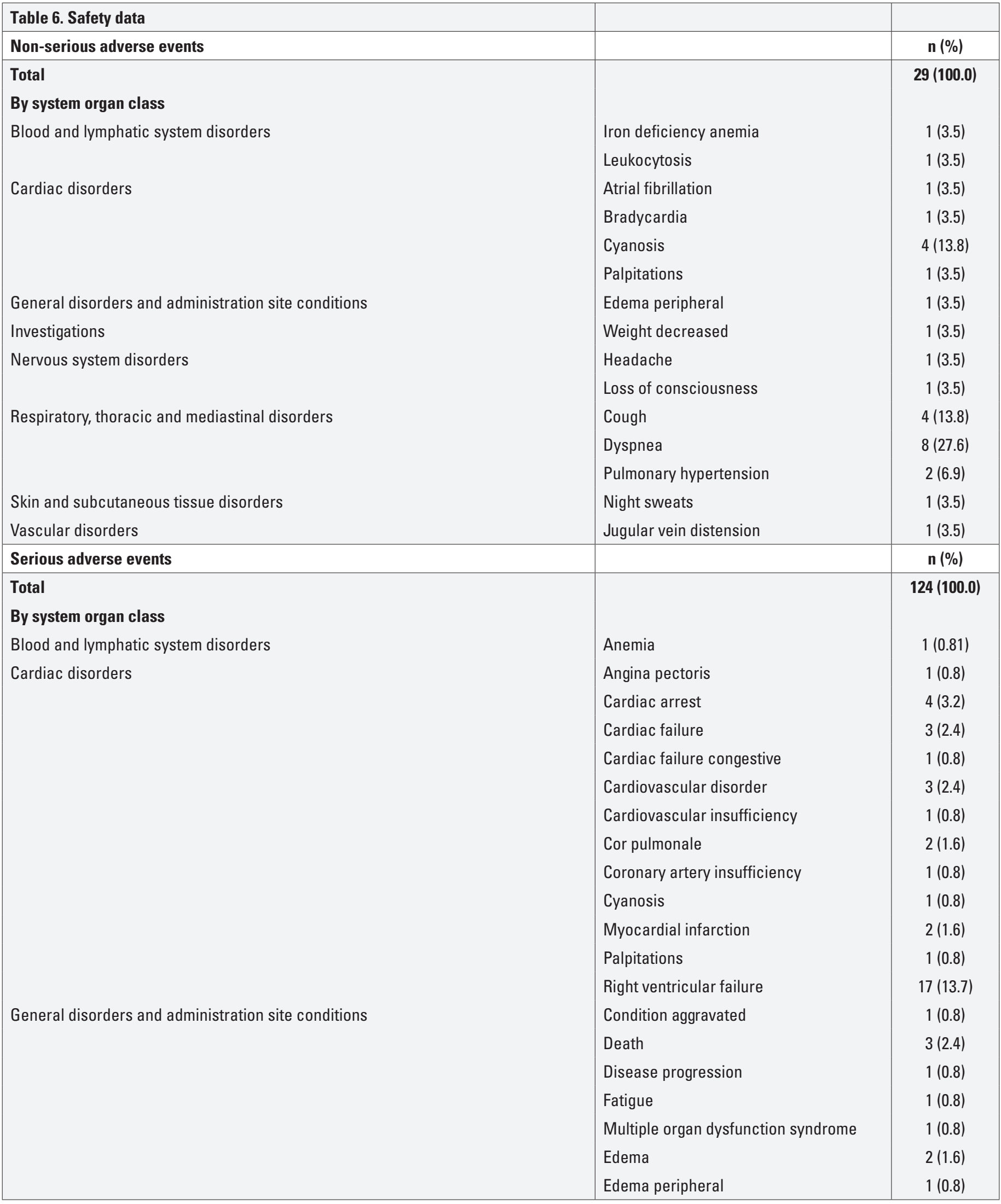




\begin{tabular}{|c|c|c|}
\hline Table 6. Safety data (continued) & & \\
\hline Infections and infestations & Bronchitis & $1(0.8)$ \\
\hline & Kidney infection & $1(0.8)$ \\
\hline & Pneumonia & $11(8.9)$ \\
\hline & Sepsis & $1(0.8)$ \\
\hline & Catheterization cardiac & $1(0.8)$ \\
\hline & International normalized ratio increased & $1(0.8)$ \\
\hline & Hemoglobin decreased & $1(0.8)$ \\
\hline Musculoskeletal and connective tissue disorders & Fistula & $1(0.8)$ \\
\hline Nervous system disorders & Syncope & $4(3.2)$ \\
\hline Renal and urinary disorders & Acute kidney injury & $2(1.6)$ \\
\hline Respiratory, thoracic and mediastinal disorders & Acute respiratory failure & $1(0.8)$ \\
\hline & Cough & $2(1.6)$ \\
\hline & Dyspnea & $12(9.7)$ \\
\hline & Hemoptysis & $2(1.6)$ \\
\hline & Interstitial lung disease & $1(0.8)$ \\
\hline & Pulmonary arterial hypertension & $7(5.7)$ \\
\hline
\end{tabular}

NYHA functional class and Borg dyspnea score, or time to clinical worsening or clinical event occurrence (28). In fact, threshold values of $6 M W D$, rather than changes induced by therapies have been suggested to be prognostic predictors, with increased risk of mortality in patients with 6MWD of $<250 \mathrm{~m}$ and substantially lower mortality in patients with 6MWD $\geq 440 \mathrm{~m}(29,30)$.

Long-term, open-label studies have also supported the clinical benefit of continued iloprost therapy in patients with PAH (27-30), including sustained effects on exercise capacity and pulmonary hemodynamics with excellent tolerability over 12 months (31), improved survival $(87 \%)$ and favorable tolerability over a period of two years (32), improved WHO functional class, 6MWD and systemic arterial oxygen saturation over 48 weeks (33), and persistence with treatment $(78 \%)$ and lack of clinical worsening ( $81 \%$ ) over one year (34). Two-year survival rate was reported to be $87 \%$ among 40 patients with idiopathic PAH (33); although in a cohort of 267 patients with PAH treated with iloprost, a three-year survival rate was reported to be
$54 \%$ despite significant improvements in physical (6MWT) and functional (WHO functional class) performance, which has been linked to use of the drug in high-risk patients with discontinuation rate as high as $75 \%(15)$.

Survival rate was $69.6 \%$ in the present cohort of patients with PAH who were treated with iloprost before to enrolment and continued therapy after the enrolment with increasing rates for combination over monotherapy. This seems consistent with the estimated three-month, six-month, one-year, and two-year event-free survival rates of $96.6 \%, 92.3 \%, 62.6 \%$, and $39.6 \%$, respectively, reported in a recent meta-analysis of 10 studies in 370 patients with PAH treated with iloprost, authors of which also emphasized a potential risk of an unsatisfactory improvement in vascular remodeling and even a decreased event-free survival rate with the use of inhaled iloprost monotherapy for a prolonged period beyond the first three months after diagnosis (23).

The median survival time of 43 months also seems consistent with the high prevalence of idiopathic PAH (74.8\%) in our cohort 
given its association with only $2.8 \pm 0.9$ years of mean survival time reported in the past studies $(35,36)$. Our findings indicated that scleroderma-related PAH was associated with 2.88-fold reduction in the risk of mortality. In addition, female sex was also associated with 3.14-fold reduction in the risk of mortality in the current study. Given the female predominance in our cohort of patients, supporting the higher prevalence of PAH among women reported in epidemiological studies, it should also be noted that male patients with PAH are considered to be affected by higher degree of right ventricular dysfunction leading to poorer outcome, alongside the better treatment results with prostacyclin analogues and endothelin receptor antagonists in female patients with PAH (37).

In a recent Bayesian network meta-analysis of 10,230 patients from 45 qualified trials on the efficacy and safety of 18 targeted drugs or drug combinations for $\mathrm{PAH}$, the combination of iloprost and bosentan was determined to perform best for lowering mean pulmonary arterial pressure (mPAP) and PVR and decreasing the incidence of clinical worsening; whereas vardenafil was considered superior to other medications in terms of low withdrawal rate and improved Borg dyspnea score; and ambrisentan plus tadalafil was considered superior in terms of efficacy on 6MWD and the occurrence of hospitalization (38). Notably, although no single therapy was concluded to be outstanding in the majority of investigated endpoints, vardenafil and iloprost+bosentan were considered to be the medications associated with a better performance in terms of both efficacy and safety (38).

Circulating levels of natriuretic peptides has been considered useful in detection of PAH or as indicators of a therapeutic response, being associated with hemodynamics and survival in patients with PAH $(39,40)$. In the phase three, double-blind Double Blind Placebo Controlled Clinical Investigation Into the Efficacy and Tolerability of Inhaled Treprostinil Sodium in Patients With Severe Pulmonary Arterial Hypertension (TRIUMPH) trial, significant difference was reported between PAH-related targeted therapies (inhaled treprostinil on background therapy with bosentan or sildenafil) vs. placebo in terms of median change in NT-proBNP (41). In addition, significantly greater decrease in NT-proBNP for combination vs. monotherapy was reported in phase $3 / 4$, double-blind The Ambrisentan and Tadalafil in Patients with Pulmonary Arterial Hypertension (AMBITION) trial (ambrisentan plus tadalafil vs. ambrisentan or tadalafil) (42) and in phase four, open-label ATHENA-1 trial (ambrisentan plus PDE5i vs. PDE5i) (43).

Our findings revealed no significant change from baseline BNP and NT-proBNP levels during follow-up visits and no impact of BNP on clinical worsening or survival, whereas significantly higher NT-proBNP levels were noted in survivors vs. non-survivors. Notably, NT-proBNP was reported to be associated with NYHA functional class, 6MWD, and survival in patients with PAH, and increased mortality risk with every 10 -fold increase in NTproBNP both at baseline [hazards ratio (HR), 4.82] and at followup (HR, 3.82) (44) and higher survival with $>15 \%$ decrease per year (45). Hence, our findings support the predictive value of NTproBNP levels for mortality and likelihood of change over time in
NT-proBNP to be more relevant than a target value in assessing response to therapy $(40,45)$.

The adverse event (dyspnea in $27.6 \%$, cough or cyanosis in $13.8 \%$ ) and serious adverse event (right ventricular failure in $13.7 \%$, dyspnea in $9.7 \%$, respiratory failure or pneumonia in $8.9 \%)$ profile of iloprost in our cohort support the safety and tolerability consistent with typical prostanoid side effects reported in past studies indicating a tendency to increased coughing and flushing and high prevalence of adverse events over two-year treatment period with right heart failure as the most frequent serious adverse event $(9,32)$.

\section{Study limitations}

Certain limitations of this study should be considered. First, owing to its observational nature, non-randomized allocation and thereby the likelihood of main selection bias and confounding is possible. Second, although the data provided was through real-life clinical practice via multicenter design at 27 centers across Turkey, a potential lack of generalizability seems another important limitation because of the relatively small sample size. Third, missing data on certain variables and the discrepancy in improvement assessed via functional capacity and 6MWD outcome were other limitations owing to the non-interventional design, precluding the possibility of drawing verifiable and generalizable scientific conclusions. Fourth, the presence of both monotherapy and combination regimens was an important limitation, which jeopardizes the concrete efficacy outcome interpretation. Nonetheless, observational studies provide important information on pre-defined cohorts of patients who represent a certain population with similar disease characteristics with primary goals of describing patient profile and clinical status and assessing treatment outcomes.

\section{Conclusion}

Our findings indicate favorable efficacy, safety, and tolerability profile of long-term iloprost treatment in monotherapy or in combination among patients with PAH, whereas improved NYHA functional class was not accompanied with improved $6 \mathrm{MWD}$ values. Clinical worsening was noted in $53.9 \%$ of patients within a median 12 -month of therapy, and survival rate was $69.6 \%$. Our findings indicate that patients' age was a risk factor for clinical worsening; whereas female sex, scleroderma subtype, and lower NT-proBNP levels were associated with significantly lower mortality risk with no significant impact of age, BNP levels, and NYHA functional class on mortality risk. Further long-term large scale studies are warranted to elucidate the mechanisms of functional and physical activity changes induced by specific targeted therapies in PAH patients and their potential value in addition to natriuretic peptides as markers of disease progression or treatment outcome.

Institutional and financial support: This study was supported by Bayer Türk.

Acknowledgments: We thank Çağla Ayhan, MD, and Prof. Şule Oktay, MD, PhD, from KAPPA Consultancy Training Research Ltd, İstanbul, 
Turkey, who provided editorial support funded by Bayer Türk.

Conflict of interest: None declared.

Peer-review: Externally peer-reviewed.

Author contributions: Concept - M.S.K., I.H., B.A., S.G., E.A., T.S., G.O., Z.P.̈., M.Y., A.B.; Design - M.S.K., I.H., B.A., S.G., E.A., T.S., G.O., Z.P.Ö., M.Y., A.B.; Supervision - M.S.K., I.H., B.A., S.G., E.A., T.S., G.O., Z.P.Ö., M.Y., A.B.; Fundings - M.S.K., I.H., B.A., S.G., E.A., T.S., G.O., Z.P.Ö., M.Y., A.B.; Materials - M.S.K., I.H., B.A., S.G., E.A., T.S., G.O., Z.P.̈., M.Y., A.B.; Data collection \&/or processing - M.S.K., I.H., B.A., S.G., E.A., T.S., G.O., Z.P.Ö., M.Y., A.B.; Analysis \&/or interpretation - M.S.K., A.B.; Literature search - M.S.K., I.H., B.A., S.G., E.A., T.S., G.O., Z.P.Ö., M.Y., A.B.; Writing - M.S.K., A.B.; Critical review - M.S.K., I.H., B.A., S.G., E.A., T.S., G.O., Z.P.Ö., M.Y., A.B.

\section{References}

1. Rosenkranz S. Pulmonary hypertension 2015: current definitions, terminology, and novel treatment options. Clin Res Cardiol 2015; 104: 197-207.

2. Galiè N, Humbert M, Vachiery JL, Gibbs S, Lang I, Torbicki A, et al.; ESC Scientific Document Group. 2015 ESC/ERS Guidelines for the diagnosis and treatment of pulmonary hypertension: The Joint Task Force for the Diagnosis and Treatment of Pulmonary Hypertension of the European Society of Cardiology (ESC) and the European Respiratory Society (ERS). Endorsed by: Association for European Paediatric and Congenital Cardiology (AEPC), International Society for Heart and Lung Transplantation (ISHLT). Eur Heart J 2016; 37 : 67-119.

3. Harrison A, Hatton N, Ryan JJ. The right ventricle under pressure: evaluating the adaptive and maladaptive changes in the right ventricle in pulmonary arterial hypertension using echocardiography (2013 Grover Conference series). Pulm Circ 2015; 5: 29-47.

4. Montani D, Günther S, Dorfmüller P, Perros F, Girerd B, Garcia G, et al. Pulmonary arterial hypertension. Orphanet J Rare Dis 2013; 8: 97.

5. Humbert M, Sitbon O, Chaouat A, Bertocchi M, Habib G, Gressin V, et al. Survival in patients with idiopathic, familial, and anorexigenassociated pulmonary arterial hypertension in the modern management era. Circulation 2010; 122: 156-63.

6. Benza RL, Miller DP, Barst RJ, Badesch DB, Frost $A E, M c G o o n$ MD. An evaluation of long-term survival from time of diagnosis in pulmonary arterial hypertension from the REVEAL Registry. Chest 2012; 142: 448-56.

7. Gessler T. lloprost delivered via the BREELIBTM nebulizer: a review of the clinical evidence for efficacy and safety. Ther Adv Respir Dis 2019; 13: 1753466619835497.

8. Gessler T. Inhalation of repurposed drugs to treat pulmonary hypertension. Adv Drug Deliv Rev 2018; 133: 34-44.

9. Olschewski H, Simonneau G, Galiè N, Higenbottam T, Naeije R, Rubin LJ, et al.; Aerosolized Iloprost Randomized Study Group. Inhaled iloprost for severe pulmonary hypertension. N Engl J Med 2002; 347: 322-9.

10. McLaughlin VV, Oudiz RJ, Frost A, Tapson VF, Murali S, Channick $\mathrm{RN}$, et al. Randomized study of adding inhaled iloprost to existing bosentan in pulmonary arterial hypertension. Am J Respir Crit Care Med 2006; 174: 1257-63.

11. Baker SE, Hockman RH. Inhaled iloprost in pulmonary arterial hy- pertension. Ann Pharmacother 2005; 39: 1265-74.

12. Richter MJ, Stollfuß B, Roitenberg A, Kleinjung F, Graeff V, Berghaus $S$, et al. Switching inhaled iloprost formulations in patients with pulmonary arterial hypertension: the VENTASWITCH Trial. Pulm Circ 2018; 8: 2045894018798921.

13. Bayer AG. Ventavis (iloprost), US prescribing information. Available from: URL: https://www.4ventavis.com/pdf/Ventavis_PI.pdf2017

14. Bayer AG. Ventavis (iloprost). Summary of Product Characteristics. 2017: 1-65. Available from: URL: http://www.ema.europa.eu/ docs/en_GB/document_library/EPAR_-_Product_Information/human/000474/WC500048691.pdf.

15. Del Pozo R, Blanco I, Hernández-González I, López-Meseguer M, López-Reyes R, Lázaro-Salvador M, et al.; REHAP investigators. Real-life experience of inhaled iloprost for patients with pulmonary arterial hypertension: Insights from the Spanish REHAP registry. Int J Cardiol 2019; 275: 158-64.

16. Avci T, Erer D, Kucuk A, Oztürk Y, Tosun M, Oktar GL, et al. The effects of iloprost on ischemia-reperfusion injury in skeletal muscles in a rodent model. J Surg Res 2014; 187: 162-8.

17. Mazzone A, Cusa C, Bucci L, Vezzoli M, Ghio S, Buggia I, et al. The effects of iloprost infusion on microcirculation is independent of nitric oxide metabolites and endothelin- 1 in chronic peripheral ischaemia. Eur J Clin Invest 1999; 29: 1-5.

18. Lang IM, Gaine SP. Recent advances in targeting the prostacyclin pathway in pulmonary arterial hypertension. Eur Respir Rev 2015; 24: 630-41.

19. McLaughlin VV, Badesch DB, Delcroix M, Fleming TR, Gaine SP, Galiè N, et al. End points and clinical trial design in pulmonary arterial hypertension. J Am Coll Cardiol 2009; 54 (1 Suppl): S97-107.

20. ATS Committee on Proficiency Standards for Clinical Pulmonary Function Laboratories. ATS statement: guidelines for the six-minute walk test. Am J Respir Crit Care Med 2002; 166: 111-7.

21. Demir R, Küçükoğlu MS. Six-minute walk test in pulmonary arterial hypertension. Anatol J Cardiol 2015; 15: 249-54.

22. Lajoie AC, Bonnet S, Provencher S. Combination therapy in pulmonary arterial hypertension: recent accomplishments and future challenges. Pulm Circ 2017; 7: 312-25.

23. Kuang H, Li Q, Yi Q, Lu T. The Efficacy and Safety of Aerosolized Iloprost in Pulmonary Arterial Hypertension: A Systematic Review and Meta-Analysis. Am J Cardiovasc Drugs 2019; 19: 393-401.

24. Ghofrani HA, Wiedemann R, Rose F, Olschewski H, Schermuly RT, Weissmann $\mathrm{N}$, et al. Combination therapy with oral sildenafil and inhaled iloprost for severe pulmonary hypertension. Ann Intern Med 2002; 136: 515-22.

25. Ghofrani HA, Rose F, Schermuly RT, Olschewski H, Wiedemann R, Kreckel $A$, et al. Oral sildenafil as long-term adjunct therapy to inhaled iloprost in severe pulmonary arterial hypertension. J Am Coll Cardiol 2003; 42: 158-64.

26. Saji T, Myoishi M, Sugimura K, Tahara N, Takeda Y, Fukuda K, et al. Efficacy and safety of inhaled iloprost in Japanese patients with pulmonary arterial hypertension - insights from the IBUKI and AIR studies. Circ J 2016; 80: 835-42.

27. Vizza CD, Badagliacca R, Messick CR, Rao Y, Nelsen AC, Benza RL. The impact of delayed treatment on 6-minute walk distance test in patients with pulmonary arterial hypertension: A meta-analysis. Int J Cardiol 2018; 254: 299-301.

28. Savarese G, Paolillo S, Costanzo P, D'Amore C, Cecere M, Losco T, et al. Do changes of 6 -minute walk distance predict clinical events in patients with pulmonary arterial hypertension? A meta-analysis of 22 randomized trials. J Am Coll Cardiol 2012; 60: 1192-201.

29. Benza RL, Miller DP, Gomberg-Maitland M, Frantz RP, Foreman AJ, 
Coffey CS, et al. Predicting survival in pulmonary arterial hypertension: insights from the Registry to Evaluate Early and Long-Term Pulmonary Arterial Hypertension Disease Management (REVEAL). Circulation 2010; 122: 164-72.

30. Barst RJ, Rubin LJ, Long WA, McGoon MD, Rich S, Badesch DB, et al.; Primary Pulmonary Hypertension Study Group. A comparison of continuous intravenous epoprostenol (prostacyclin) with conventional therapy for primary pulmonary hypertension. N Engl J Med 1996; 334: 296-301.

31. Hoeper MM, Schwarze M, Ehlerding S, Adler-Schuermeyer A, Spiekerkoetter E, Niedermeyer J, et al. Long-term treatment of primary pulmonary hypertension with aerosolized iloprost, a prostacyclin analogue. N Engl J Med 2000; 342: 1866-70.

32. Olschewski H, Hoeper MM, Behr J, Ewert R, Meyer A, Borst MM, et al. Long-term therapy with inhaled iloprost in patients with pulmonary hypertension. Respir Med 2010; 104: 731-40.

33. Westerhof BE, Saouti N, van der Laarse WJ, Westerhof N, Vonk Noordegraaf $A$. Treatment strategies for the right heart in pulmonary hypertension. Cardiovasc Res 2017; 113: 1465-73.

34. Channick RN, Frantz RP, Kawut SM, Palevsky H, Tumuluri R, Sulica $\mathrm{R}$, et al. A multicenter, retrospective study of patients with pulmonary arterial hypertension transitioned from parenteral prostacyclin therapy to inhaled iloprost. Pulm Circ 2013; 3: 381-8.

35. D'Alonzo GE, Barst RJ, Ayres SM, Bergofsky EH, Brundage BH, Detre KM, et al. Survival in patients with primary pulmonary hypertension. Results from a national prospective registry. Ann Intern Med 1991; 115: 343-9.

36. Ogawa A, Ejiri K, Matsubara H. Long-term patient survival with idiopathic/heritable pulmonary arterial hypertension treated at a single center in Japan. Life Sci 2014; 118: 414-9.

37. Marra AM, Benjamin N, Eichstaedt C, Salzano A, Arcopinto M, Gargani $L$, et al. Gender-related differences in pulmonary arterial hypertension targeted drugs administration. Pharmacol Res 2016; 114: 103-9.

38. Wang S, Yu M, Zheng X, Dong S. A Bayesian network meta-analysis on the efficacy and safety of eighteen targeted drugs or drug combinations for pulmonary arterial hypertension. Drug Deliv 2018; 25: 1898-909.

39. Steiner MK, Preston IR, Klinger JR, Hill NS. Pulmonary hypertension: inhaled nitric oxide, sildenafil and natriuretic peptides. Curr Opinion Pharmacol 2005; 5: 245-50.

40. McMahon TJ, Bryan NS. Biomarkers in Pulmonary Vascular Disease: Gauging Response to Therapy. Am J Cardiol 2017; 120: S8995.

41. McLaughlin VV, Benza RL, Rubin LJ, Channick RN, Voswinckel R, Tapson VF, et al. Addition of inhaled treprostinil to oral therapy for pulmonary arterial hypertension: a randomized controlled clinical trial. J Am Coll Cardiol 2010; 55: 1915-22.

42. Galiè N, Barberà JA, Frost AE, Ghofrani HA, Hoeper MM, McLaughlin VV, et al.; AMBITION Investigators. Initial Use of Ambrisentan plus Tadalafil in Pulmonary Arterial Hypertension. N Engl J Med 2015; 373: 834-44.

43. Oudiz R, Shapiro S, Torres F, Feldman J, Frost A, Allard M, et al. ATHENA-1: hemodynamic improvements following the addition of ambrisentan to background PDE5i therapy in patients with pulmonary arterial hypertension. Chest 2011; 140 (Suppl): 905A.

44. Williams MH, Handler CE, Akram R, Smith CJ, Das C, Smee J, et al. Role of N-terminal brain natriuretic peptide (N-TproBNP) in scleroderma-associated pulmonary arterial hypertension. Eur Heart $\mathrm{J}$ 2006; 27: 1485-94.

45. Mauritz GJ, Rizopoulos D, Groepenhoff H, Tiede H, Felix J, Eilers P, et al. Usefulness of serial N-terminal pro-B-type natriuretic peptide measurements for determining prognosis in patients with pulmonary arterial hypertension. Am J Cardiol 2011; 108: 1645-50. 